\title{
Isolation and identification of biological characteristics of porcine circovirus type 2 (PCV2) from pigs in southern Vietnam
}

\author{
Phuong T. T. Le ${ }^{1 *}$, Hai N. Nguyen ${ }^{2}$, Hong T. T. Nguyen ${ }^{1}$, Hung Dang ${ }^{1}$, Ngon V. Quach $^{1}$, \\ Phuc N. H. Nguyen ${ }^{1}$, Liem T. Nguyen ${ }^{1}$, Hanh X. Tran ${ }^{1}$, \& Dung V. Nguyen ${ }^{1}$ \\ ${ }^{1}$ Navetco National Veterinary Joint Stock Company, Ho Chi Minh City, Vietnam \\ ${ }^{2}$ Faculty of Animal Science and Veterinary Medicine, Nong Lam University, Ho Chi Minh City, Vietnam
}

\section{ARTICLE INFO} \\ Research paper \\ Received: February 23, 2018 \\ Revised: March 28, 2018 \\ Accepted: April 11, 2018

\section{Keywords} \\ Isolation \\ Porcine circovirus type 2 \\ Vaccine

\section{${ }^{*}$ Corresponding author} \\ Le Thi Thu Phuong \\ Email: lephuong.navetco@gmail.com
}

\begin{abstract}
This study aimed to isolate and examine the biological characteristics of PCV2 field strains circulating in Vietnam for further study in producing vaccine against PMWS (postweaning multisystemic wasting syndrome). Eighteen PCV2 strains were successfully isolated and belonged to genotype PCV2b (9 strains), PCV2d (6 strains) and recombinant (3 strains). The viral titers of PCV2 isolates at the third passages in PK15A cells were in the range from 1.67 to $5,50 \log _{10} \mathrm{TCID}_{50} / \mathrm{mL}$. Three PCV2 field strains with stable viral titers $\left(\geq 5,0 \log _{10} \mathrm{TCID}_{50} / \mathrm{mL}\right)$ through passages, which belonged to different genotypes, were selected as master seed for studying of PCV2 vaccines.
\end{abstract}

Cited as: Le, P. T. T., Nguyen, H. N., Nguyen, H. T. T., Dang, H., Quach, N. V., Nguyen, P. N. H., Nguyen, L. T., Tran, H. X., \& Nguyen, D. V. (2018). Isolation and identification of biological characteristics of porcine circovirus type 2 (PCV2) from pigs in southern Vietnam. The Journal of Agriculture and Development 17(4), 68-75. 


\title{
Phân lập và xác định đặc tính sinh học của một số chủng porcine circovirus type 2 (PCV2) từ heo nuôi tại khu vực phía nam Việt Nam
}

\author{
Lê Thị Thu Phương ${ }^{1 *}$, Nguyễn Ngọc Hải ${ }^{2}$, Nguyễn Thị Thu Hồng ${ }^{1}$, \\ Đặng Hùng ${ }^{1}$, Quách Vô Ngôn ${ }^{1}$, Nguyễn Ngọc Hồng Phúc ${ }^{1}$, \\ Nguyễn Tấn Liêm ${ }^{1}$, Trần Xuân Hạnh ${ }^{1}$ và Nguyễn Văn Dung ${ }^{1}$ \\ ${ }^{1}$ Công Ty Cổ Phần Thuốc Thú Y Trung Ương Navetco, TP. Hồ Chí Minh \\ ${ }^{2}$ Khoa Chăn Nuôi Thú Y, Trường Đại Học Nông Lâm TP. Hồ Chí Minh, TP. Hồ Chí Minh
}

\author{
THÔNG TIN BÀI BÁO \\ Bài báo khoa học \\ Ngày nhận: 23/02/2018 \\ Ngày chỉnh sửa: 28/03/2018 \\ Ngày chấp nhận: 11/04/2018 \\ Từ khóa \\ Phân lập \\ Porcine circovirus type 2 \\ Vắc-xin \\ *Tác giả liên hệ \\ Lê Thị Thu Phương \\ Email: lephuong.navetco@gmail.com
}

\section{TÓM TẮT}

Trong nghiên cứu này các chủng PCV2 lưu hành ở Việt Nam đã được phân lập và khảo sát đặc tính sinh học nhằm phục vụ cho việc nghiên cứu sản xuất vắc-xin phòng $\mathrm{PMWS}$ trên heo. Nghiên cứu đã phân lập được 18 chủng PCV2 thuộc các genotype PCV2b (9 chủng), $\mathrm{PCV} 2 \mathrm{~d}$ (6 chủng) và nhóm PCV2 tái tổ hợp (3 chủng) từ các mẫu bệnh phẩm heo dương tính $\mathrm{PCV} 2$, có biểu hiện triệu chứng và bệnh tích bệnh do circovirus trên heo (porcine circovirus disease - PCVD). Hiệu giá vi-rút đạt được trên môi trường tế bào PK15A dao động từ 1,67 đến $5,50 \log _{10} \mathrm{TCID}_{50} / \mathrm{mL}$ ở lần tiếp đời thứ 3. Chọn được 3 chủng thuộc 3 genotype khác nhau có hiệu giá cao ổn định qua các lần tiếp đời $\left(\geq 5,0 \log _{10} \mathrm{TCID}_{50} / \mathrm{mL}\right)$ dùng làm giống gốc để nghiên cứu sản xuất vắc-xin PCV2.

\section{1. Đặt Vấn Đề}

PCV2 liên quan đến một số bệnh trên heo, gọi chung là các bệnh do circovirus trên heo (porcine circovirus diseases - PCVDs) (Segalés \& ctv., 2012), gây thiệt hại nghiêm trọng trong chăn nuôi heo, trong đó quan trọng nhất là Hội chứng còi cọc trên heo sau cai sữa (postweaning multisystemic wasting syndrome - PMWS). Các nghiên cứu thí nghiệm và thực địa đã chứng minh tính hiệu quả của việc phòng PMWS bằng vắc-xin về lâm sàng và cận lâm sàng (Chae, 2012). Việc tiêm vắc-xin PCV2 giúp cải thiện tăng trọng bình quân hàng ngày, giảm tỷ lệ chết, tỷ lệ loại thải, giảm lượng vi-rút bài thải cũng như giảm bệnh tích vi thể ở các mô bạch huyết (Kristensen \& ctv., 2011; Fraile \& ctv., 2012; Seo \& ctv., 2014). Ở Việt Nam hiện nay chỉ lưu hành các loại vắc-xin PCV2 thương mại ngoại nhập, chủ yếu dựa trên
PCV2 thuộc genotype 2a, trong khi đó PCV2 lưu hành ở Việt Nam chủ yếu thuộc genotype $\mathrm{PCV} 2 \mathrm{~b}$ và $\mathrm{PCV} 2 \mathrm{~d}$ và nhóm tái tổ hợp (Huynh \& ctv., 2013; Nguyen \& ctv. 2013; Pham \& ctv., 2017). Takahagi \& ctv. (2010) cho rằng, genotype của PCV2 có thể ảnh hưởng đến hiệu quả phòng PMWS bằng vắc-xin. Trong nghiên cứu sản xuất vắc-xin nói chung, vắc-xin $\mathrm{PCV} 2$ nói riêng, việc lựa chọn chủng vi-rút để làm giống gốc (master seed) và giống sản xuất (working seed) là khâu trọng yếu đầu tiên. Việc chọn chủng vi-rút phù hợp phải dựa trên các thông tin về dịch tễ học của bệnh. Vi-rút được chọn phải đáp ứng được các tiêu chí quan trọng như (1) Chủng vi-rút đó phải có khả năng gây đáp ứng miễn dịch bảo hộ chống lại tác nhân gây bệnh, đây là tiêu chí quan trọng nhất trong việc lựa chọn chủng vi-rút vắcxin; (2) Chủng vi-rút vắc-xin phải có phổ kháng nguyên rộng, có thể kích thích sinh miễn dịch bảo 
hộ chống lại càng nhiều chủng thực địa càng tốt; (3) Về cơ bản, chủng vi-rút vắc-xin có nguồn gốc từ các phân lập thực địa, các chủng này có thể có độc lực cao, độc lực trung bình hoặc không có độc lực. Do đó, tùy đặc tính độc lực của chủng vắc-xin mà chế tạo các loại vắc-xin khác nhau (sống nhược độc, vô hoạt); (4) Khả năng nhân lên của chủng vắc-xin trong môi trường nuôi cấy (tế bào sơ cấp, tế bào dòng, phôi trứng...) để có thể phục vụ sản xuất vắc-xin ở quy mô lớn (Soulebot \& ctv., 1997).Trong nghiên cứu này, các phân lập PCV2 được khảo sát các đặc tính sinh học nhằm chọn lựa chủng PCV2 phù hợp để nghiên cứu sản xuất vắc-xin phòng các bệnh do circovirus trên heo.

\section{Vật Liệu và Phương Pháp Nghiên Cứu}

\subsection{Vật liệu}

Mẫu bệnh phẩm: 21 mẫu bệnh phẩm (9 mẫu hạch, 9 mẫu phổi, 2 mẫu huyết thanh và 1 mẫu lách) từ 21 heo được thu thập từ năm 2007 dến 2016 từ 11 tỉnh thành phía Nam Việt Nam, dương tính với $\mathrm{PCV} 2$ bằng xét nghiệm $\mathrm{PCR}$, được xác định genotype bằng việc phân tích trình tự nucleotide toàn bộ gien $\mathrm{ORF} 2$, được lưu trữ ở $-70^{0} \mathrm{C}$ tại phòng thí nghiệm Trung tâm Nghiên cứu Thú $\mathrm{y}$ - Công ty cổ phần thuốc thú $\mathrm{y}$ trung ương NAVETCO.

Chủng NAVET-vietnam3/2004 (có mã số Genbank JX506730) (Nguyen \& ctv., 2008) cũng được tiếp tục nghiên cứu đặc tính sinh học.

Tế bào: tế bào PK15A (không nhiễm PCV1) do phòng thí nghiệm quốc gia Úc - AAHL (Australian Animal Health Laboratory, Geelong, Australia) cung cấp.

\subsection{Phương pháp phân lập vi-rút}

Nghiền mẫu mô thành huyễn dịch $10 \%$ trong môi trường EMEM (Eagle's Minimum Essential Medium), đông tan 1 lần ở $-70^{\circ} \mathrm{C}$, ly tâm 4000 vòng/30 phút, lấy dịch nổi. Xử lý dịch nổi bằng chloroform trong 10 phút (nhằm tinh sạch mẫu và loại bỏ các vi-rút có vỏ bọc khác), ly tâm 3000 vòng/10 phút, thu dịch nổi. Dùng dịch nổi này để phân lập vi-rút PCV2 trên tế bào PK15A (dạng tế bào tươi, tế bào sau khi được tách rời bằng trypsin và hoàn nguyên trong môi trường EMEM có chứa $10 \%$ huyết thanh bào thai bê) bằng cách nhiễm $0,5 \mathrm{~mL}$ huyễn dịch mẫu vào $10 \mathrm{~mL}$ huyễn dịch tế bào dạng tươi, cho hỗn dịch trên vào nuôi cấy trên chai tế bào $25 \mathrm{~cm}^{2}$, ủ ở $37^{0} \mathrm{C}$. Sau 24 giờ tế bào phát triển khoảng $50-60 \%$ thì được xử lý bằng D-glucosamine $300 \mathrm{mM}$ trong 30 phút ở $37^{0} \mathrm{C}$, tiếp tục nuôi thêm 48 giờ. Vi-rút được tiếp đời 3 lần trên môi trường tế bào và xác định sự hiện diện bằng phương pháp IPX (immunoperoxidase) hoặc PCR (polymerase chain reaction).

Phản ứng IPX trên môi trường tế bào PK15A dùng để phát hiện $\mathrm{PCV} 2$ theo quy trình của AAHL. Cụ thể, tế bào PK15A sau khi được gây nhiễm và nuôi cấy trên đĩa nuôi tế bào có đường kính $20 \mathrm{~mm}$ (quy trình tương tự như nuôi trên chai tế bào đường kính $25 \mathrm{~cm}^{2}$ ), được loại bỏ môi trường nuôi cấy, rửa 2 lần bằng $\mathrm{PBS}$ và cố định bằng dung dịch chứa formaldehyde $10 \%$ và $0,1 \%$ NP40, ủ ở nhiệt độ phòng/20 phút, rửa 4 lần bằng $\mathrm{PBS}$. Sau đó, ủ 1 giờ ở $37^{0} \mathrm{C}$ với kháng thể đặc hiệu kháng $\mathrm{PCV} 2$, rửa 4 lần bằng $\mathrm{PBS}$ chứa $0,1 \%$ Tween 20 (PBST). Tiếp tục ủ 1 giờ ở $37^{0} \mathrm{C}$ với protein $\mathrm{A}$ (conjugate), rửa 4 lần bằng $\mathrm{PBST}$. Cuối cùng, cho cơ chất amino-ethyl-carbazole ủ ở nhiệt độ phòng trong 15 phút. Đọc kết quả dưới kính hiển vi soi ngược, tế bào chứa PCV2 sẽ có màu đỏ gạch.

\subsection{Phương pháp xác định genotype}

Sử dụng cặp mồi capFw 5'-CTT TTT TAT CAC TTC GTA ATG-3' và cap Rw 5'-CGC ACT TCT TTC GTT TTC-3' được tham khảo từ Fort \& ctv. (2007) để khuếch đại phát hiện sự hiện diện của $\mathrm{ADN} \mathrm{PCV} 2$ và giải trình tự xác định genotype (dựa vào $\mathrm{ORF} 2)$. Các thành phần cho một phản ứng $\mathrm{PCR}$ bao gồm $\mathrm{PCR}$ buffer $1 \mathrm{X}, 1,5$ $\mathrm{mM} \mathrm{MgCl}_{2}, 0,2 \mathrm{mM}$ dNTPs, $0,5 \mu \mathrm{M}$ mỗi đoạn mồi, 2,5 UI Taq DNA polymerase và $1 \mu \mathrm{l} A D N$ khuôn mẫu $/ 25 \mu \mathrm{l}$. Quy trình PCR: $94^{0} \mathrm{C} / 2$ phút, 35 chu kỳ $\left(94^{0} \mathrm{C} 15\right.$ giây, $55^{0} \mathrm{C} 1$ phút, $68^{0} \mathrm{C} 20$ giây), $68^{0} \mathrm{C} 7$ phút, giữ ở $4^{0} \mathrm{C}$. Điện di sản phẩm PCR bằng agarose $2 \%$ trong dung dịch TAE $1 \mathrm{X}$, ở 90V, 130mA, trong 30 phút. Sản phẩm khuếch đại có kích thước 760 bp.

Phân tích trình tự và xây dựng cây di truyền: Sản phẩm PCR được gởi giải trình tự nucleotide tại $1^{\text {st }}$ BASE - Malaysia. Trình tự chuỗi nucleotide gien ORF2 của các phân lập PCV2 (Bảng 1) được phân tích bằng phần mềm BioEdit version 7.2.5 (2013). Cây di truyền được thiết lập bằng phần mềm MEGA version 5.2.2 (2012) theo phương pháp Maximum Likelihood (ML) với bootstrap 1000 lần lặp lại. 


\subsection{Phương pháp chuẩn độ vi-rút trên môi trường tế bào}

Hiệu giá PCV2 được xác định theo nguyên tắc pha loãng tới hạn (end point dilution). Dịch vi-rút được pha loãng bậc 10 trong môi trường EMEMtừ $10^{-1}, 10^{-2}, 10^{-3}, \ldots, 10^{-6}$. Sự hiện diện của PCV2 được phát hiện thông qua phương pháp nhuộm IPX. Hiệu giá vi-rút được thể hiện bằng liều gây nhiễm $50 \%$ tế bào (tissue culture infective doses - TCID $_{50} / \mathrm{mL}$ ) và được tính theo công thức Reed-Muench (1938).

\subsection{Khả năng nhân lên của $\mathrm{PCV} 2$ trên môi trường tế bào PK15A}

Xác định đặc điểm phát triển của các chủng $\mathrm{PCV} 2$ bằng đường cong sinh trưởng (one-step growth curve). Chủng phân lập (ở lần tiếp đời thứ 7) được gây nhiễm trên môi trường tế bào PK15A (dạng tế bào tươi) với hệ số gây nhiễm MOI là 0,1 (Fenaux \& ctv., 2003). Sau 24 giờ tế bào phát triển phủ kín khoảng 50-60\% đáy chai nuôi cấy, được xử lý bằng D-glucosamine $300 \mathrm{mM}$ trong 30 phút ở $37^{0} \mathrm{C}$. Sau đó tế bào nhiễm được rửa 2 lần bằng $\mathrm{PBS}$ và cho vào môi trường nuôi cấy mới. Tế bào nuôi cấy được thu hoạch theo thời gian mỗi 12 giờ đến 120 giờ sau gây nhiễm. Mỗi chủng được khảo sát lặp lại 2 lần.

\section{6. Đánh giá tính ổn định qua các lần tiếp đời}

Các chủng PCV2 được tiếp đời liên tục trên tế bào PK15A để đánh giá khả năng nhân lên của vi-rút qua các lần tiếp đời. Dựa trên kết quả khảo sát đường cong sinh trưởng, từ lần tiếp đời thứ 8 trở đi các chủng được tiếp đời với hệ số $\mathrm{MOI}=$ 0,1 và được thu hoạch ở thời điểm thích hợp, tùy từng chủng, để đạt được hiệu giá vi-rút tối ưu.

\section{Kết Quả và Thảo Luận}

\subsection{Kết quả phân lập PCV2}

Từ các mẫu bệnh phẩm dương tính với $\mathrm{ADN}$ PCV2 vi-rút được phân lập trên môi trường tế bào PK15A,phát hiện vi-rút trong tế bào nhiễm bằng phương pháp PCR và IPX (Hình 1 ), kết quả sau 3 lần tiếp đời phân lập được 18/21 (85,71\%) mẫu dương tính PCV2 (Bảng 1). Trong các loại mẫu bệnh phẩm dùng phân lập PCV2 thì mẫu hạch đạt tỉ lệ phân lập dương tính cao nhất $100 \%$ (9/9) với hiệu giá vi-rút ở lần tiếp đời thứ 3 biến động từ 1,67 đến $5,50 \log _{10} \mathrm{TCID}_{50} / \mathrm{mL}$. PCV2 cũng phân lập được từ mẫu huyết thanh nhưng hiệu giá vi-rút ở lần tiếp đời thứ 3 khá thấp, chỉ đạt $1,67 \log _{10} \mathrm{TCID}_{50} / \mathrm{mL}$. Tuy nhiên, chưa phân lập được PCV2 từ mẫu lách $(0 / 1)$, điều này có thể do số lượng mẫu lách dùng trong nghiên cứu này quá ít. Đã phân lập được $9 / 18$ (50,00\%) mẫu PCV2 dương tính thuộc genotype PCV2b, 6/18 (33,33\%) mẫu dương tính thuộc genotype PCV2d và $3 / 18(16,67 \%)$ mẫu dương tính thuộc nhóm PCV2 tái tổ hợp (dựa vào việc phân tích trình tự nucleotide toàn bộ gien ORF2 để xác định genotype của các phân lập). Ngoài ra, PCV2 có thể nuôi cấy được trên môi trường tế bào ST (swine testis cell line - tế bào tinh hoàn heo). Tuy nhiên, hiệu giá vi-rút đạt được không cao như khi phân lập trên tế bào PK15A (số liệu không công bố).
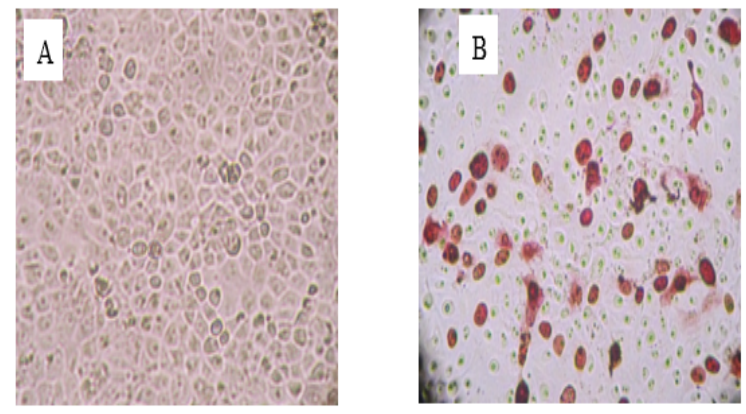

Hình 1. Phương pháp nhuộm IPX phát hiện PCV2 phân lập trên môi trường tế bào PK15A. (A) Tế bào PK15A đối chứng (không nhiễm PCV2); (B) Tế bào PK15A nhiễm PCV2 (bắt màu đỏ gạch).

Ngoài phân lập được PCV2 từ mẫu bệnh phẩm trên heo sau cai sữa (Hình 2), chúng tôi còn phân lập được PCV2 từ mẫu huyết thanh nái có biểu hiện sẩy thai và từ mẫu phổi lấy từ thai khô (Hình 3). Các PCV2 được phân lập từ những heo nái có biểu hiện rối loạn sinh sản đều thuộc genotype PCV2b. Các phân lập BinhDinh5/2013, Binh Dinh6/2013 được phân lập từ mẫu huyết thanh heo nái dương tính với vi-rút PRRS, có biểu hiện sẩy thai và sinh ra heo con chết tươi. Riêng phân lập NAVET-TpHCM8/2016 được phân lập từ phổi của thai khô ở heo nái có biểu hiện rối loạn sinh sản và âm tính với các tác nhân gây rối loạn sinh sản khác như PRRSV, CSFV, PPV. Điều này cho thấy, $\mathrm{PCV} 2$ ngoài liên quan đến PMWS còn liên quan đến rối loạn sinh sản trên heo nái như nhận định của West \& ctv. (1999). Tương tự, một số tác giả khác cũng phân lập được 
PCV2 từ mẫu mô (tim, phổi, gan và thận) của thai sẩy (Meehan \& ctv., 2001) từ huyết thanh của heo con sinh ra chết tươi (stillborn) (Farnham \& ctv., 2003). Kết quả của các nghiên cứu này cho thấy, $\mathrm{PCV} 2$ có khả năng truyền dọc và gây chết thai trong điều kiện thực địa.

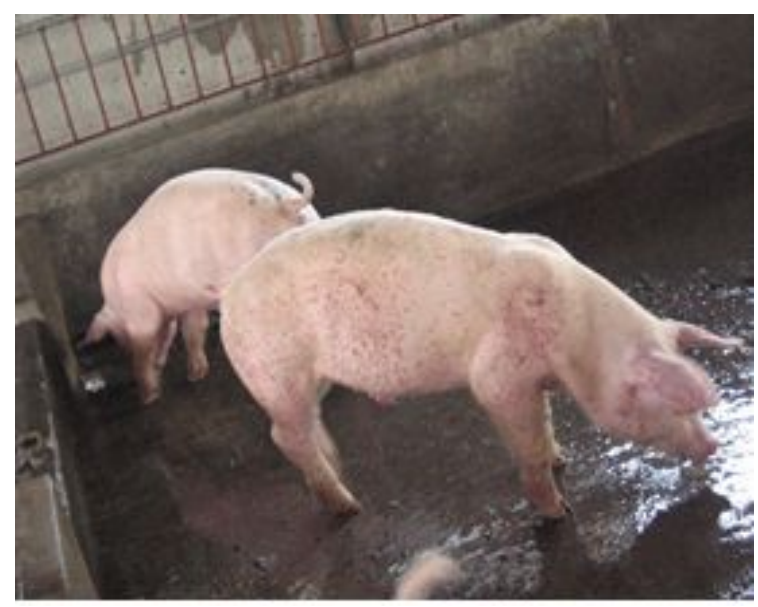

Hình 2. Heo có biểu hiện viêm da.

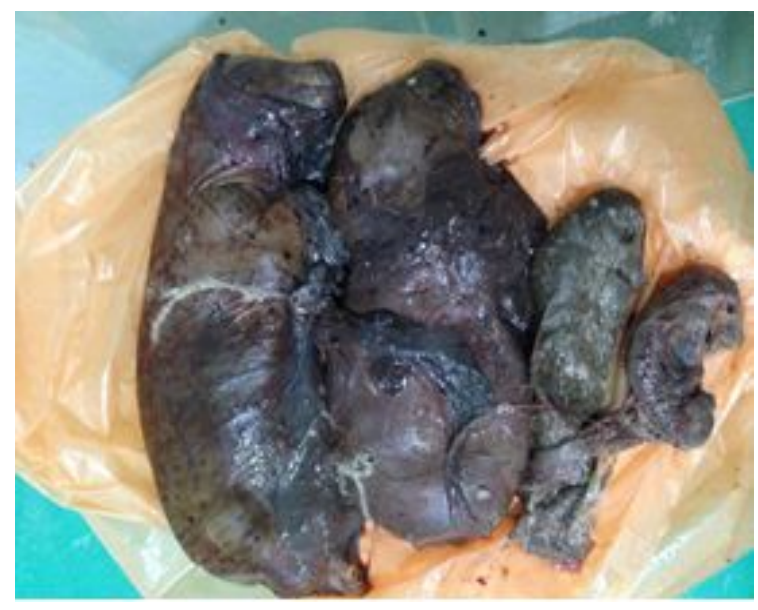

Hình 3. Thai khô ở các giai đoạn khác nhau.

\subsection{Khả năng gây bệnh tích tế bào}

In vitro, tế bào $\mathrm{PK} 15$ (dòng không nhiễm $\mathrm{PCV}$ ) được sử dụng rộng rãi để phân lập PCV2. Chưa có báo cáo về PCV2 gây bệnh tích tế bào điển hình (cytopathic effect - $\mathrm{CPE}$ ) nên sự hiện diện của vi-rút thường được xác định thông qua việc nhuộm miễn dịch huỳnh quang (immunofluorescence - IF) hoặc miễn dịch enzyme IPX tế bào nhiễm (Allan \& Ellis, 2000). Tuy nhiên, kết quả nghiên cứu của Dvorak \& ctv. (2013) cho thấy, khi gây nhiễm PCV2 trên tế bào thận bào thai heo VR1BL (porcine fetal retina cell line) ở nồng độ thấp (multiplicity of infection, $\mathrm{MOI}=0,01$ ) tế bào bị nhiễm vẫn có thể phát triển sau khi tiếp đời nhưng khi gây nhiễm PCV2 với nồng độ cao $(\mathrm{MOI}=1)$, phần lớn các tế bào bị nhiễm không thể phát triển được khi tiếp đời, có sự thay đổi về hình dạng tế bào xảy ra sau 3 ngày gây nhiễm, và xảy ra hiện tượng tế bào chết theo chương trình (apoptosis). Trong nghiên cứu này, cũng ghi nhận được sự thay đổi hình dạng tế bào PK15A ba ngày sau gây nhiễm $\mathrm{PCV} 2$ với hệ số $\mathrm{MOI} \geq 0,05$ : tế bào có vẻ to hơn, co tròn, đậm màu và có nhiều tế bào chết so với tế bào đối chứng không nhiễm (Hình $4 \mathrm{~A}$ và $4 \mathrm{C}$ ), nhưng với hệ số MOI thấp 0,01 - 0,02 thì không có sự khác biệt về hình dạng giữa tế bào bị nhiễm vi-rút và tế bào đối chứng (Hình 4A và 4B) (số liệu chưa công bố).
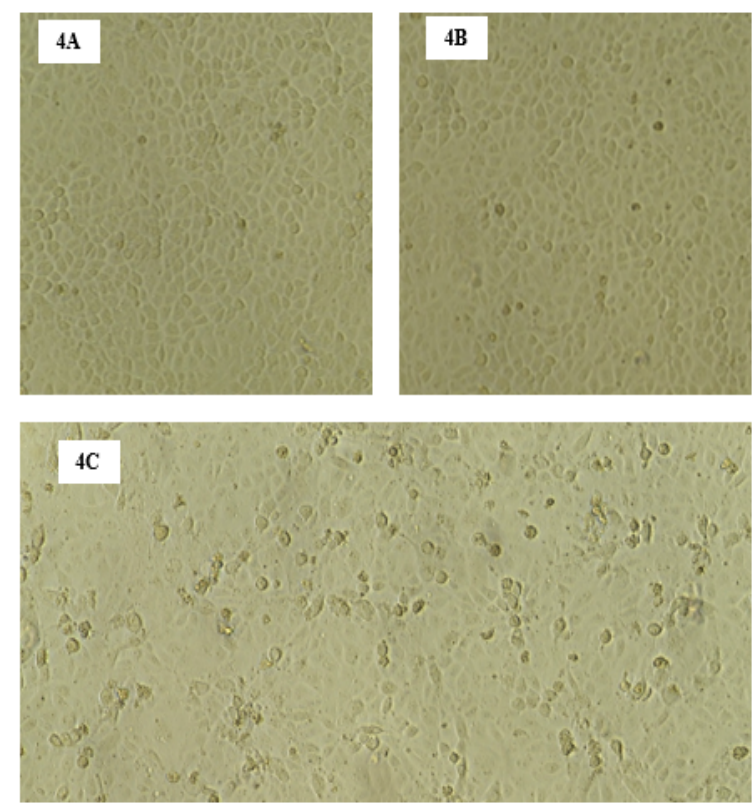

Hình 4. Hình dạng tế bào tế bào PK15A: (A) Đối chứng, $(\mathrm{B}) \mathrm{MOI}=0,01$ và $(\mathrm{C}) \mathrm{MOI}=0,1$ (ghi nhận tại thời điểm 96 giờ sau nhiễm PCV2).

\subsection{Khả năng nhân lên của PCV2 trên môi trường tế bào PK15A}

Những phân lập có hiệu giá vi-rút cao nhất ở mỗi genotype ở lần tiếp đời thứ 3 - được kiểm tra tính thuần khiết, không tạp nhiễm các vi-rút khác - được chọn để tiếp tục nghiên cứu các đặc tính sinh học trên môi 
Bảng 1. Kết quả phân lập PCV2 trên môi trường tế bào PK15A

\begin{tabular}{|c|c|c|c|c|c|c|c|}
\hline STT & Ký hiệu mẫu & Geno & $\begin{array}{l}\text { Loại } \\
\text { mẫu }\end{array}$ & $\begin{array}{l}\begin{array}{l}\text { Loại } \\
\text { heo }\end{array} \\
\end{array}$ & $\begin{array}{c}\text { Triệu chứng*** } \\
\text { lâm sàng }\end{array}$ & $\begin{array}{l}\text { Kết quả } \\
\text { phân lập }\end{array}$ & $\begin{array}{c}\text { Hiệu giá (P3) } \\
\log _{10} \text { TCID }_{50} / \mathrm{mL} \\
\end{array}$ \\
\hline 1 & CaMau/2007 & $2 \mathrm{~b}$ & Phổi & $\begin{array}{l}\text { Sau } \\
\text { cai } \\
\text { sữa }\end{array}$ & Mắc bệnh tai xanh & - & - \\
\hline 2 & KhanhHoa/2007 & $2 \mathrm{~b}$ & Phổi & $\begin{array}{l}\text { Sau } \\
\text { cai } \\
\text { sưa }\end{array}$ & Còi cọc & - & - \\
\hline 3 & BinhDuong1/2009 & $2 \mathrm{~b}$ & Hạch & $\begin{array}{l}\text { Sau } \\
\text { cai } \\
\text { sữa }\end{array}$ & Còi cọc & + & 1,67 \\
\hline 4 & NAVET-BinhDuong2/2009 & $2 \mathrm{~b}$ & Hạch & $\begin{array}{l}\text { Sau } \\
\text { cai } \\
\text { sữa }\end{array}$ & Còi cọc & + & 3,67 \\
\hline 5 & BinhDuong3/2009 & $2 \mathrm{~b}$ & Hạch & $\begin{array}{l}\text { Sau } \\
\text { cai } \\
\text { sưa }\end{array}$ & Còi cọc & + & 1,67 \\
\hline 6 & BinhDuong4/2009 & $2 \mathrm{~b}$ & Hạch & $\begin{array}{l}\text { Sau } \\
\text { cai } \\
\text { sưa }\end{array}$ & Còi cọc & + & 3,67 \\
\hline 7 & NAVET-DongNai2/2009 & $2 \mathrm{~b}$ & Hạch & $\begin{array}{l}16 \\
\text { tuần }\end{array}$ & $\begin{array}{l}\text { Còi cọc, } \\
\text { khó thở, } \\
\text { viêm da, } \\
\text { da nhợt nhạt }\end{array}$ & + & 4,50 \\
\hline 8 & TpHCM6/2010 & $2 \mathrm{~b}$ & Phổi & $\begin{array}{l}\text { Sau } \\
\text { cai } \\
\text { sữa }\end{array}$ & $\begin{array}{l}\text { Triệu chứng hô hấp: } \\
\text { ho, khó thở }\end{array}$ & + & 1,67 \\
\hline 9 & BinhDinh5/2013 & $2 \mathrm{~b}$ & $\begin{array}{l}\text { Huyết } \\
\text { thanh }\end{array}$ & Nái & $\begin{array}{l}\text { Mắc bệnh tai xanh, } \\
\text { sinh ra heo con chết }\end{array}$ & + & 1,67 \\
\hline 10 & BinhDinh6/2013 & $2 \mathrm{~b}$ & $\begin{array}{l}\text { Huyết } \\
\text { thanh }\end{array}$ & Nái & $\begin{array}{c}\text { Mắc bệnh tai xanh, } \\
\text { sẩy thai }\end{array}$ & + & 1,67 \\
\hline 11 & NAVET-TpHCM8/2016 & $2 \mathrm{~b}$ & Phổi & Thai & Thai khô & + & 4,00 \\
\hline 12 & NAVET-LongAn2/2012 & $2 \mathrm{~d}-2$ & Hạch & $\begin{array}{l}\text { Sau } \\
\text { cai } \\
\text { sữa }\end{array}$ & $\begin{array}{c}\text { Mắc bệnh tai xanh, } \\
\text { viêm da }\end{array}$ & + & 5,50 \\
\hline 13 & BinhDinh1/2013 & $2 \mathrm{~d}-2$ & Phổi & Thai & Thai sẩy & + & 1,67 \\
\hline 14 & LamDong1/2013 & $2 \mathrm{~d}-2$ & Phổi & $\begin{array}{l}12 \\
\text { tuần } \\
\text { Sauy }\end{array}$ & $\begin{array}{c}\text { Mắc bệnh tai xanh, } \\
\text { viêm da }\end{array}$ & + & 1,67 \\
\hline 15 & NAVET-NgheAn1/2015 & $2 \mathrm{~d}-2$ & Hạch & $\begin{array}{l}\text { Sau } \\
\text { cai } \\
\text { sữa }\end{array}$ & Còi cọc & + & 5,50 \\
\hline 16 & NAVET-NgheAn2/2015 & $2 \mathrm{~d}-2$ & Phổi & $\begin{array}{l}\text { Sau } \\
\text { cai } \\
\text { sữa }\end{array}$ & Còi cọc & + & 5,00 \\
\hline 17 & NAVET-BenTre/2014 & $2 \mathrm{~d}-1$ & Hạch & $\begin{array}{l}\text { Cai } \\
\text { sữa }\end{array}$ & $\begin{array}{c}\text { Không có } \\
\text { dữ liệu }\end{array}$ & + & 5,00 \\
\hline 18 & CanTho/2008 & $\operatorname{Re}^{* *}$ & Lách & $\begin{array}{l}\text { Sau } \\
\text { cai } \\
\text { sưa }\end{array}$ & $\begin{array}{c}\text { Không có } \\
\text { dữ liệu }\end{array}$ & - & - \\
\hline 19 & TpHCM4/2010 & $\operatorname{Re}$ & Hạch & $\begin{array}{l}\text { Sau } \\
\text { cai } \\
\text { sữa }\end{array}$ & $\begin{array}{c}\text { Mắc bệnh tai xanh, } \\
\text { viêm da }\end{array}$ & + & 4,33 \\
\hline 20 & BinhDuong6/2012 & $\operatorname{Re}$ & Phổi & $\begin{array}{l}1 \\
\text { tuần } \\
\text { tuổi }\end{array}$ & $\begin{array}{l}\text { Gầy trơ xương, } \\
\text { tiêu chảy nặng }\end{array}$ & + & 1,67 \\
\hline 21 & BinhDinh3/2013 & $\operatorname{Re}$ & Phổi & $\begin{array}{l}\text { Sau } \\
\text { cai } \\
\text { sữa }\end{array}$ & $\begin{array}{c}\text { Không có } \\
\text { dữ liệu }\end{array}$ & + & 1,67 \\
\hline 22 & NAVET-vietnam3/2004* & $\operatorname{Re}$ & Hạch & $\begin{array}{l}\text { Không } \\
\text { có } \\
\text { dữ liệu }\end{array}$ & $\begin{array}{l}\text { Không có } \\
\text { dữ liệu }\end{array}$ & + & 4,50 \\
\hline
\end{tabular}

*: Nguyen \& ctv., 2008. Phân tích di truyền circovirus lợn typ 2 (PCV2) trên lợn tại khu vực Nam bộ. Tạp chí KHKT Thú Y XV(2): 5-12; **: Re: Nhóm tái tổ hợp (recombination); ***: Các heo được xác định mắc bệnh tai xanh thông qua triệu chứng lâm sàng, bệnh tích và xác định có sự hiện diện của vi-rút PRRS trong mẫu bệnh phẩm bằng phương pháp RT-PCR.

trường tế bào PK15A. Các phân lập đó là khảo sát về đặc tính gây bệnh và tính sinh miễn NAVET-DongNai2/2009 thuộc genotype PCV2b, dịch trên heo kết quả nghiên cứu được đăng trong NAVET-LongAn2/2012 thuộc genotype PCV2d Tạp chí Thú y số 2, 2008). Các phân lập này và NAVET-vietnam3/2004 thuộc nhóm tái tổ hợp được tiếp tục lựa chọn trong khảo sát các đặc (riêng phân lập NAVET-vietnam3/2004 đã được tính sinh học như tính ổn định qua các lần tiếp nhóm tác giả Nguyen \& ctv. (2008) phân lập và đời, đặc điểm phát triển và thời gian thu hoạch 
Bảng 2. Hiệu giá của các chủng NAVET-DongNai2/2009, NAVET-LongAn2/2012 và NAVET-vietnam3/2004 qua các lần tiếp đời trên tế bào PK15A

\begin{tabular}{cccc}
\hline \multirow{2}{*}{ Tiếp đời } & \multicolumn{3}{c}{ Hiệu giá vi-rút $\left(\log _{10}\right.$ TCID $\left._{50} / \mathrm{mL}\right)$} \\
\cline { 2 - 4 } & NAVET-DongNai2/2009 & NAVET-LongAn2/2012 & NAVET-vietnam3/2004 \\
\hline P3 & 4,50 & 5,50 & 4,50 \\
P4 & 4,50 & 5,50 & 4,50 \\
P5 & 4,67 & 5,50 & 4,50 \\
P6 & 5,00 & 5,00 & 4,50 \\
P7 & 5,50 & 5,00 & 5,50 \\
P8 & 5,00 & 6,67 & 5,00 \\
P9 & 5,33 & 5,50 & 5,67 \\
P10 & 5,50 & 6,00 & 5,67 \\
P11 & 5,33 & 6,00 & 5,50 \\
P12 & 5,33 & 5,50 & 5,50 \\
P13 & 5,50 & 5,50 & 5,67 \\
P14 & 5,50 & 5,50 & 5,50 \\
P15 & 5,33 & 5,50 & 5,67 \\
Trung bình & 5,15 & 5,59 & 5,21 \\
SD & 0,38 & 0,43 & 0,52 \\
\hline
\end{tabular}

để đạt hiệu giá vi-rút tối ưu khi nuôi cấy trên môi trường tế bào PK15A.

Kết quả đường cong sinh trưởng các chủng NAVET-DongNai2/2009, NAVETLongAn2/2012 và NAVET-vietnam3/2004 được biểu diễn qua Hình 5 . Trung bình hiệu giá vi-rút (thể hiện dưới dạng $\log 10 \quad \mathrm{TCID}_{50} / \mathrm{mL}$ ) qua các thời điểm thu hoạch khác nhau của chủng NAVET-vietnam3/2004 cao nhất $(5,20 \pm 0,31$ $\log 10 \mathrm{TCID}_{50} / \mathrm{mL}$ ), kế đến là chủng NAVETLongAn2/2012 (4,75 $\pm 0,60 \log _{10}$ TCID $\left._{50} / \mathrm{mL}\right)$ và thấp nhất là chủng NAVET-DongNai2/2009 $\left(4,30 \pm 0,62 \log _{10} \mathrm{TCID}_{50} / \mathrm{mL}\right)(P<0,01)$. Ngoài ra, có sự khác biệt về trung bình hiệu giá vi-rút ở các thời điểm thu hoạch khác nhau $(P$ $<0,01)$. Phân tích đường cong sinh trưởng cho thấy, thời điểm thu hoạch để đạt hiệu giá vi-rút cao nhất khác nhau tùy theo chủng PCV2. Cụ thể, đối với chủng NAVET-vietnam3/2004 là 72 giờ, chủng NAVET-DongNai2/2009 là 84 giờ và chủng NAVET-LongAn2/2012 là 108 giờ sau nhiễm. Từ kêt quả nghiên cứu này giúp chọn lựa được thời gian thu hoạch thích hợp cho từng chủng để đạt hiệu giá vi-rút tối ưu trong chế tạo vắc-xin.

\subsection{Tính ổn định qua các lần tiếp đời}

Các chủng NAVET-DongNai2/2009, NAVETLongAn2/2012 và NAVET-vietnam3/2004 được tiếp đời liên tục trên tế bào PK15A, kết quả

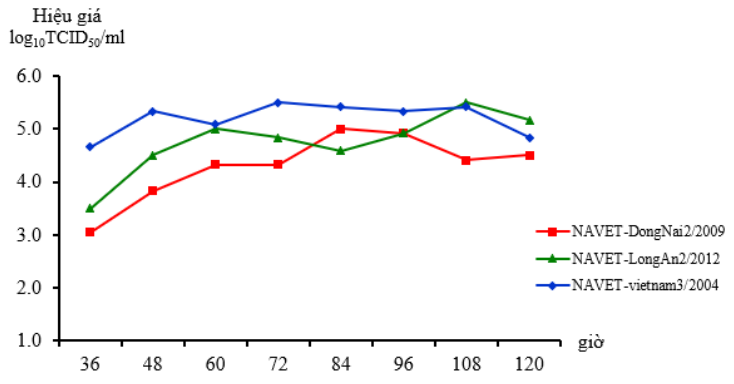

Hình 5. Đường cong sinh trưởng của các chủng virút chọn làm giống chế vắc-xin.

được trình bày qua Bảng 2. Trung bình chung qua 15 lần tiếp đời hiệu giá vi-rút của chủng NAVET-LongAn2/2012 cao nhất $(5,59 \pm 0,43$ $\log _{10} \mathrm{TCID}_{50} / \mathrm{mL}$ ) kế đến là chủng NAVETvietnam3/2004 $\left(5,21 \pm 0,52 \log _{10} \mathrm{TCID}_{50} / \mathrm{mL}\right)$ và thấp nhất là chủng NAVET-DongNai2/2009 $\left(5,15 \pm 0,38 \log _{10}\right.$ TCID $\left._{50} / \mathrm{mL}\right)$, không có sự khác biệt về trung bình hiệu giá giữa 3 chủng này qua 15 lần tiếp đời $(P>0,05)$. Điều này cho thấy 3 chủng này phát triển ổn định trên tế bào $\mathrm{PK} 15 \mathrm{~A}$ với hiệu giá $\geq 5,0 \log _{10} \mathrm{TCID}_{50} / \mathrm{mL}$.

\section{Kết Luận}

Đã phân lập thành công được 18 chủng PCV2 từ 21 mẫu bệnh phẩm dương tính ADN-PCV2 từ heo có triệu chứng và bệnh tích liên quan đến các bệnh do circovirus trên heo (PCVD). Trong 
đó, 9/18 mẫu dương tính thuộc genotype PCV2b, 6/18 mẫu dương tính thuộc PCV2d và $3 / 18$ mẫu thuộc nhóm PCV2 tái tổ hợp. Hiệu giá vi-rút đạt được dao động từ 1,67 đến $5,50 \log _{10} \mathrm{TCID}_{50} / \mathrm{mL}$ ở lần tiếp đời thứ 3 .Việc phân lập PCV2 từ mẫu hạch đạt tỉ lệ dương tính và hiệu giá đạt được cao hơn so với các loại mẫu bệnh phẩm khác. Ngoài ra, cũng phân lập được PCV2 từ mẫu phổi của thai khô với hiệu giá vi-rút khá cao 4,0 $\log _{10} \mathrm{TCID}_{50} / \mathrm{mL}$.

Ba chủng thuộc 3 genotype khác nhau đó là chủng NAVET-DongNai2/2009 (PCV2b), NAVET-LongAn2/2012 (PCV2d) và NAVETvietnam3/2004 (nhóm PCV2 tái tổ hợp), có hiệu giá vi-rút đạt được khá ổn định qua các lần tiếp đời và đều đạt $\geq 5,0 \log _{10} \mathrm{TCID}_{50} / \mathrm{mL}$, có thể phục vụ cho việc nghiên cứu sản xuất vắc-xin phòng bệnh do circovirus trên heo.

\section{Tài Liệu Tham Khảo (References)}

Allan, G. M., \& Ellis, J. A. (2000). Porcine Circoviruses: A Review. Journal of Veterinary Diagnostic Investigation 12(1), 3-14.

Chae, C. (2012). Commercial porcine circovirus type 2 vaccines: efficacy and clinical application. Veterinary Journal 194(2), 151-157.

Dvorak C. M. T., Puvanendiran S., \& Murtaugh M. P. (2013). Cellular pathogenesis of porcine circovirus type 2 infection. Virus Research 174(1-2), 60-68.

Farnham, M. W., Choi, Y. K., Goyal, S. M., \& Joo, H. S. (2003). Isolation and characterization of porcine circovirus type-2 from sera of stillborn fetuses. The Canadian Journal of Veterinary Research 67(2), 108-113.

Fenaux, M., Opriessnig, T., Halbur, P. G., \& Meng, X. J. (2003). Immunogenicity and pathogenicity of chimeric infectious DNA clones of pathogenic porcine circovirus type 2 (PCV2) and nonpathogenic PCV1 in weanling pigs. Journal of Virology 77(20), 11232-11243.

Fraile, L., Sarasola P., Sinovas, N., Nofrarías, M., LópezJimenez, R., López-Soria, S., Sibila, M., \& Segalés, J. (2012). Inactivated PCV2 one shot vaccine applied in 3 -week-old piglets: Improvement of production parameters and interaction with maternally derived immunity. Vaccine 30(11), 1986-1992.

Fort, M., Olvera, A., Sibila, M., Segalés, J., \& Mateu, E. (2007). Detection of neutralizing antibodies in postweaning multisystemic wasting syndrome (PMWS) affected and non PMWS affected pigs. Veterinary $M i$ crobiology 125(3-4), 244-255.

Huynh, T. M. L., Nguyen, B. H., Nguyen, V. G., Dang, H. A, Mai, T. N., Tran, T. H. G., Ngo, M. H., Le, V. T., Vu, T. N., Ta, T. K. C., Kim, H. K., \& Park, B. K. (2013). Phylogenetic and Phylogeographic Analyses of Porcine Circovirus Type 2 Among Pig Farms in
Vietnam. Transboundary and emerging diseases 61(6), e25-e34.

Kristensen, C. S., Baadsgaard, N. P., \& Toft, N. (2011). A meta-analysis comparing the effect of PCV2 vaccines on average daily weight gain and mortality rate in pigs from weaning to slaughter. Preventive veterinarymedicine 98(4), 250-258.

Meehan, B. M., McNeilly, F., McNair, I., Walker, I., Ellis, J. A., Krakowk, S., \& Allan, G. M. (2001). Isolation and characterization of porcine circovirus 2 from cases of sow abortion and porcine dermatitis and nephropathy syndrome. Archives of Virology 146(4), 835-842.

Nguyen, H. N., Vo, H. K., \& Nguyen, H. T. K. (2013). Genetic analysis of porcine circovirus type 2 (PCV2) in post-weaning piglets in Dong Nai province and Ho Chi Minh city. Journal of Veterinary Sciences and Techniques XX(1), 22-28.

Nguyen, H. T. T., Le, P. T. T., Dang, H., Nguyen, H. T., Nguyen, H. N., Chris, J. M., \& Darren S. (2008). Genetic analysis of circovirus type 2 (PCV2) in pigs in the southern region of Vietnam. Journal of Veterinary Sciences and Techniques XV(2), 5-12.

Pham, Q. H., Pham, H. C., \& Huynh, Le. T. M. (2017). Characteristics of molecular epidemiology of porcine circovirus genotype 2d (PCV2d) circulating in Vietnam. Vietnam Journal of Agricultural Sciences 15(5), 553-564.

Segalés, J. (2012). Porcine circovirus type 2 (PCV2) infections: clinical signs, pathology and laboratory diagnosis. Virus Research 164(1-2), 10-19.

Seo, H. W., Han, K., Park, C., \& Chae, C. (2014). Clinical, virological, immunological and pathological evaluation of four porcine circovirus type 2 vaccines. Veterinary Journal 200(1), 65-70.

Soulebot, J. P., Folkers, C., Taylor, J., \& Pastoret, P. P. (1997). Properties of vaccines. In Pastoret, P. P., Blancou, J., Vannier, P., \& Verschueren, C. (Eds.). Veterinary Vaccinology (ed., 159-166). Amsterdam, Netherlands: Elsevier.

Takahagi, Y., Nishiyama, Y., Toki, S., Yonekita, T., Morimatsu, F., \& Murakami, H. (2008). Genotypic change of porcine circovirus type 2 on Japanese pig farms as revealed by restriction fragment length polymorphism analysis. Journal of Veterinary Medical Science 70(6), 603-606.

West, K. H., Bystrom, J. M., Wojnarowicz, C., Shantz, N., Jacobson, M., Allan, G. M., Haines, D. M., Clark, E. G., Krakowka, S., McNeilly, F., Konoby, C., Martin, K., \& Ellis, J. A. (1999). Myocarditis and abortion associated with intrauterine infection of sows with porcine circovirus 2. Journal of Veterinary DiagnosticInvestigation 11(6), 530-532. 